\title{
Research and Development of Economical CNC Software for 2D Lean Friction Stir Welding Machine
}

\author{
Diop Sokhna Anta Balla, Zhou Hu, Xu Chi \\ Department of Mechanical Engineering, Donghua University, Shanghai, China \\ Email address: \\ Sokhnanta@hotmail.fr (D. S. A. Balla), tigerzhou@dhu.edu.cn (Zhou Hu),1743044687@qq.com (Xu Chi)
}

\section{To cite this article:}

Diop Sokhna Anta Balla, Zhou Hu, Xu Chi. Research and Development of Economical CNC Software for 2D Lean Friction Stir Welding Machine. International Journal of Mechanical Engineering and Applications. Vol. 6, No. 3, 2018, pp. 59-63.

doi: 10.11648/j.ijmea.20180603.13

Received: April 12, 2018; Accepted: May 17, 2018; Published: June 20, 2018

\begin{abstract}
This project is developing a two-dimensional friction stir machine, relatively low cost to achieve four axis friction stir welding equipment with real-time servo control, where the corresponding trajectory planning function in cam is relatively independent by making a full use of Galil motion controller has a strong multi axis linkage control capability and fast real-time communication capabilities and the Galil motion controllet G code analysis software module is developped. This paper is studying the trajectory planning software system design and development of friction stir for different trajectories in the plan and is aiming to solve the motion trajectory control problem with complex welding path. A deep study of three polynomial spline function trajectory planner is done, and the complex motion trajectory of the multi axis welding machine controlled by acceleration and speed is realized. The micro arc transition approximation method is applied to optimize the inflection point with abrupt change of track path and achieve smooth inflection motion.
\end{abstract}

Keywords: Friction Stir Welding (FSW), Galil Motion Controller, G Code, Speed Optimization

\section{Introduction}

Invented in December 1991 by The Welding Institute (TWI), Friction stir welding (FSW) is a quite new process for welding different kinds of materials, which provides an excellent welding quality. FSW process does not require a use of welding material and does not produce fume gas. FSW can be used to weld metals such as aluminum alloy, copper, magnesium, zinc, steel and titanium. Regarding to its benefits, FSW has been widely used in heavy industries such as ship, aircraft, railway, national defense and military [1]. Although the research of friction stir welding technology is more mature, in practical engineering application, a reform of the traditional high grade numerical control machine is often applied, and there a revolution a high speed of a friction head and an extension through the spindle into the joint of the workpiece shown in figure 1, and the relative motion of the $\mathrm{XY}$ axis is formed to complete the welding.

In FSW process, the weld is effective even before materials reach their melting temperature, so no porosity is observe on the welding surface, therefore a high-quality weld is obtained. Sometimes it even happens that the weld become stronger than the base material. Usually materials properties do not notice changes in their proprieties. [2] With FSW process, the welding problem of the low melting point alloy has been solved successfully.

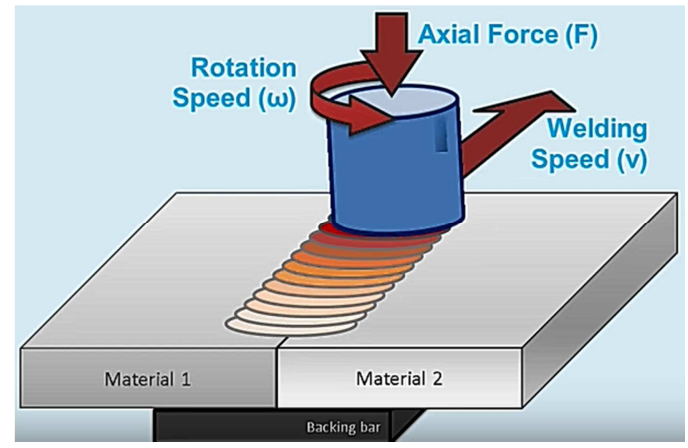

Figure 1. Principle of FSW process.

But the Friction Stir Welding method using the existing numerical control equipment has hindered the popularization of the technology in civil field because of equipment high cost, which is not facilitating the integration of military and civilian. [3]. 


\section{FSW Process Main Parameters}

The FSW head shape, for main parameters which have considering effect on weld forming and joint mechanical properties, are essentially the rotating speed (n), the welding speed (v) and the welding pressure (p). [4]

(1) FSW Rotation speed (n)

According to the stir welding head rotational speed, when the welding speed is slow and welding surface become bright and smooth, but in the back of weld can be seen as the local fusion and we got emergence of shrinkage. The shrinkage will disappear whenever the welding speed (v) increase. As well as a constant growing of the welding speed, weld surface roughness variation will be clearly seen, the sample cut will find tunnel defects along the cross section of the weld, and when the welding speed is too much fast, more defections tunnel type will be noticed, or even a trench will appear on the weld surface. [5]

In FSW process there is a relation between the rotational speed and heat produced during the welding process which can be expressed as:

$$
\mathrm{E}=\pi \omega \mu \mathrm{F}\left(\mathrm{r}_{0}^{2}+\mathrm{r}_{0} \mathrm{r}_{1}+\mathrm{r}_{1}^{2}\right) /\left[45\left(\mathrm{r}_{0}+\mathrm{r}_{1}\right) \mathrm{v}\right]
$$

Where $\omega$ is the rotation speed, $\mathrm{r} / \mathrm{min}$; $\mu$ the friction coefficient; $\mathrm{F}$ tool shoulder pressure, $\mathrm{N} / \mathrm{mm}$; $\mathrm{r} 0$ is the shoulder radius, $\mathrm{mm}$; $\mathrm{r} 1$ pin Radius, $\mathrm{mm}$; $\mathrm{v}$ welding speed, $\mathrm{mm} / \mathrm{min}$.

(2) FSW welding speed (v)

During FSW process, the welding heads of particular type of welding, if welding speed and welding pressure remain constant, the rotational speed is low, the generated friction heat not enough, weld metal cannot reach the thermoplastic state, to form a thermal plastic flow layer. That makes the FSW process to be not able to form a closed weld by milling in the metal, which appears in the weld groove surface. Welding heat production depends on rotation speed variation. [6]

In FSW process velocity can be express as:

$$
\mathrm{v}_{\mathrm{r}}=\omega \mathrm{r}-\mathrm{U} \sin \theta
$$

Where $r$ is radial distance from tool axis

$\theta$ is the angle between the radial vector $r$ and the welding direction

$\mathrm{U}$ is welding tool constant speed.

(3) FSW axial shoulder pressure (p)

In FSW process, an enough pressure applied is so far enough to obtain the require friction welding heat between the FSW head and the welding pieces. At the same time, the welding pressure plays a role in limiting the overflow of plastic fluid and ensuring the formation of weld bead. [7] Therefore, the welding pressure size plays a big part in weld quality. Its influence might be considered.

\section{Difficulty in FSW Welding Process}

The flexibility of the modified milling machine for FSW process limits the complexity of the welding path (linear, curve). The number of axes (degrees of freedom), the machine has usually established the flexibility of the machine. One dimensional welding path is the least complex, requiring minimal flexibility (small number of shafts). The simplest version of this machine has only two axes $(\mathrm{x}, \mathrm{y})$.

\section{Technical Difficulties and Solutions}

The modified milling machine which is presently used for FSW process has limits in welding complex paths and it is known that the flexibility of every machine is defined by the number of degree of freedom present in this machine and the minimum require on each is at least one dimensional. In our case, to be able to provide a solution in welding different trajectories, at least a three-dimensional machine is required. There the main problem in FSW industrialization is coming over: how to insure the loading capacity to the welding machine in different parts of the welding for a path where we know that parts can be different in material, size, geometry, the required precision, etc. So, the welding parts or the welding head are going to be able to move to ensure requirements for the program building by that the degree of freedom of the machine will be increased. That is what not so frequently seen from conventional milling machines. The diversity and complexity of trajectories require more flexibility from welding machines.

Why not choosing a robot arm to be the welding head of FSW?

A robot arm system is going to weld easily curve, circular and straight joints which request a system of two degree of freedoms (DOFs) at least. Further studies were already oriented to those arm robots in order to bring flexibility in FSW welding process. But a robot controlling system is not the most economic system which is going to help FSW process to widen its user's world [8].

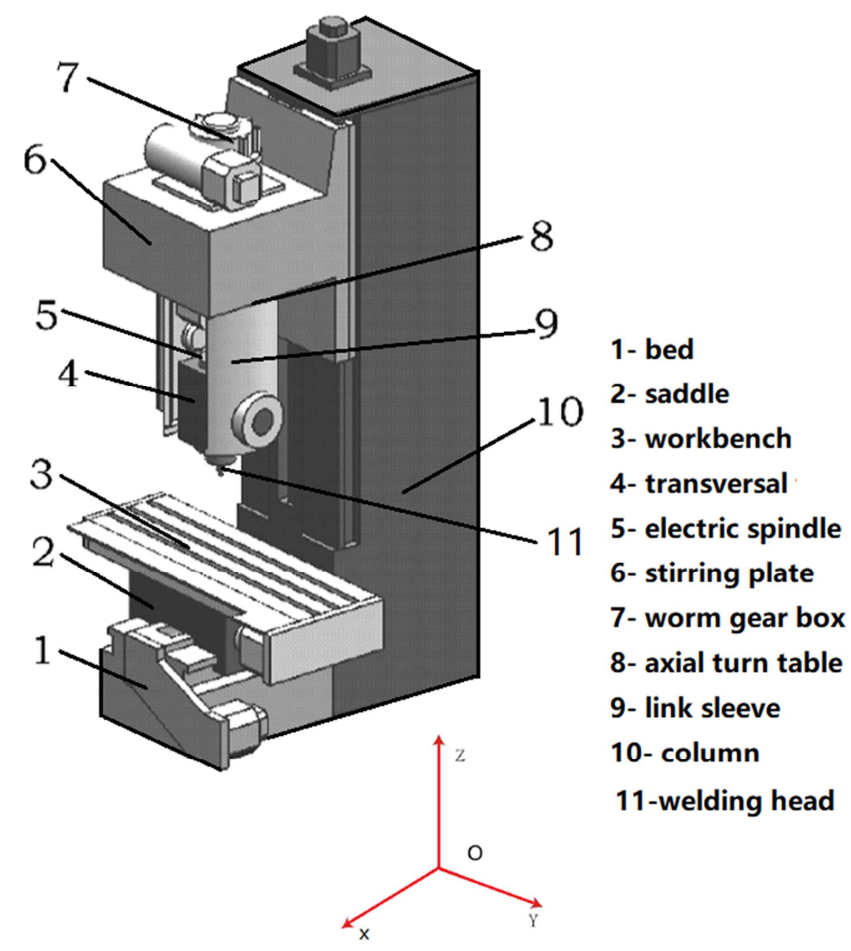

Figure 2. FSW process machine structure. 
In this paper, the work will consist to find a simpler and economical prototype of FSW process to weld curve which can be a good alternative to robot arm. The working system will be a system of four axes which has a large workspace and each axe is going to be driven by a driver where linear encoder gives high precision of guiding and localization. [9]

From the machine structure according to figure 2, it can be easily seen that the work pieces can move through $\mathrm{X}, \mathrm{Y}$ axis and there an additional $\mathrm{W}$ axis is built to provide more flexibility while welding arcs.

\section{Trajectory Planner}

For this paper study case, trajectories shown as in figure 3 are considered:

A continuous space trajectory is supposed, from time $t_{0}$ up to $t_{\mathrm{f}}$ Split into $\mathrm{N}$ segments. Each segment can be approximated by three polynomial spline functions, and the trajectories on the connecting points of the adjacent two segment boundaries are kept continuous. For that it is necessary to know the coordinates and velocities of the points at each end. [10]

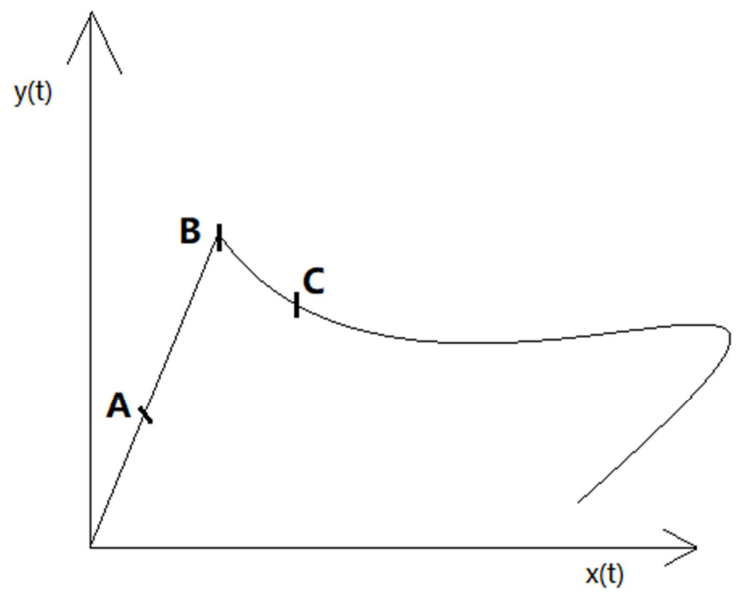

(a)

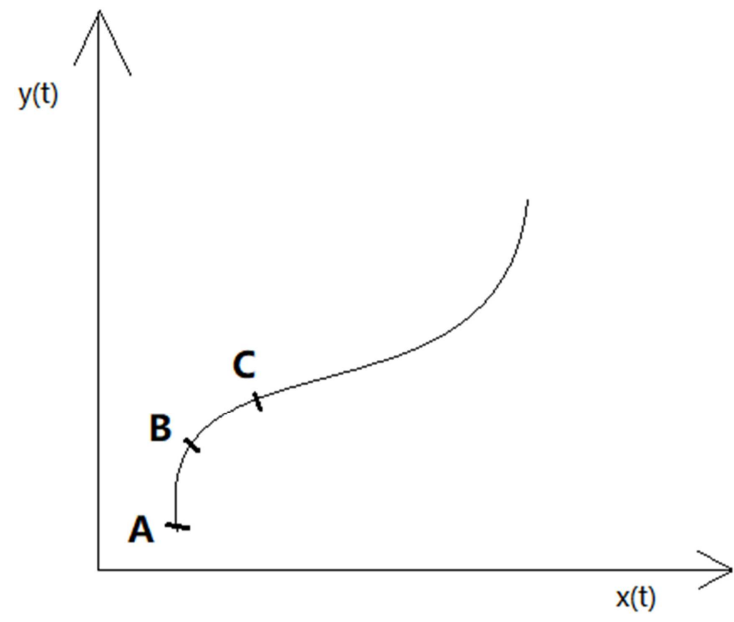

(b)

Figure 3. Different welding trajectories.
Order symbol $\mathrm{r}_{\mathrm{i}}=\left(\mathrm{x}_{\mathrm{i}}, \mathrm{y}_{\mathrm{i}}, \mathrm{z}_{\mathrm{i}}\right)^{\mathrm{T}}$ and $\dot{\mathrm{r}_{\mathrm{i}}}=\left(\mathrm{x}_{\mathrm{i}}, \dot{\mathrm{y}}_{\mathrm{i}}, \dot{\mathrm{z}_{\mathrm{i}}}\right)^{\mathrm{T}}, i$ $=0,1, \ldots, \mathrm{N}$, The position and velocity vector of a given reference point on a spatial trajectory. For the first $\mathrm{i}$ section $\mathrm{t}_{\mathrm{i}-1} \leq \mathrm{t} \leq \mathrm{t}_{\mathrm{i}}$, the relative time variable is introduced

$$
\tau=\frac{\mathrm{t}-\mathrm{t}_{\mathrm{i}-1}}{\mathrm{t}_{\mathrm{i}}-\mathrm{t}_{\mathrm{i}-1}}, \quad 0 \leq \tau \leq 1
$$

And it is represented by three polynomial spline functions of points and points

$$
\mathrm{r}(\tau)=\mathrm{a}_{1}+\mathrm{a}_{2} \tau+\mathrm{a}_{3} \tau^{2}+\mathrm{a}_{4} \tau^{3}
$$

\section{Controlling Welding Trajectory Velocity Difficulties}

When the rotational speed (n) doesn 't reach a suitable speed, there is no way to have a right material flow which give a good welding quality. With rotational speed increasing, the friction coefficient between tools and materials increase at the same time, there the input heat is also increasing by at the same time. By heat input increasing, the material will soften faster than normal way. Further, with the rotational speed (n) as a kind of low, the wear of the mixing head is too fast which increase the axial force. [11]

\section{Trajectory Velocity Expression}

As following with the already describe function in trajectory planner

To $\tau$ The first derivative

$$
\mathrm{V}=\frac{\mathrm{dr}(\tau)}{\mathrm{d} \tau}=\dot{\mathrm{r}}(\mathrm{t}) \bullet\left(\mathrm{t}_{\mathrm{i}}-\mathrm{t}_{\mathrm{i}-1}\right)=\mathrm{a}_{2}+2 \mathrm{a}_{3} \tau+3 \mathrm{a}_{4} \tau^{2}
$$

Then boundary conditions are as follows:

$$
\begin{aligned}
& \tau=0, \quad r(0)=r_{i-1}, \quad \frac{d r(0)}{d \tau}=\dot{r}_{i-1}\left(t_{i}-t_{i-1}\right) \\
& \tau=0, \quad r(1)=r_{i}, \quad \frac{d r(1)}{d \tau}=\dot{r}_{i}\left(t_{i}-t_{i-1}\right)
\end{aligned}
$$

Substituting these boundary conditions into equations (3) and (5) can be obtained:

$$
\begin{aligned}
& \mathrm{r}_{\mathrm{i}-1}=\mathrm{a}_{1} \\
& \dot{\mathrm{r}}_{\mathrm{i}-1}\left(\mathrm{t}_{\mathrm{i}}-\mathrm{t}_{\mathrm{i}-1}\right)=\mathrm{a}_{2} \\
& \mathrm{r}_{\mathrm{i}}=\mathrm{a}_{1}+\mathrm{a}_{2}+\mathrm{a}_{3}+\mathrm{a}_{4} \\
& \mathrm{r}_{\mathrm{i}}\left(\mathrm{t}_{\mathrm{i}}-\mathrm{t}_{\mathrm{i}-1}\right)=\mathrm{a}_{2}+2 \mathrm{a}_{3}+3 \mathrm{a}_{4}
\end{aligned}
$$

By solving the above simultaneous equations, the 4 undetermined coefficients of three polynomial spline functions $\mathrm{a}_{1}, \mathrm{a}_{2}, \mathrm{a}_{3}, \mathrm{a}_{4}$ can be determined 


$$
\begin{aligned}
\mathrm{a}_{1} & =\mathrm{r}_{\mathrm{i}-1} \\
\mathrm{a}_{2} & =\dot{\mathrm{r}}_{\mathrm{i}-1} \bullet\left(\mathrm{t}_{\mathrm{i}}-\mathrm{t}_{\mathrm{i}-1}\right)=\frac{\mathrm{dr}(\mathrm{i}-1)}{\mathrm{d} \tau} \\
\mathrm{a}_{3} & =-3 \mathrm{r}_{\mathrm{i}-1}-2 \dot{\mathrm{r}}_{\mathrm{i}-1}\left(\mathrm{t}_{\mathrm{i}}-\mathrm{t}_{\mathrm{i}-1}\right)+3 \mathrm{r}_{\mathrm{i}}-\mathrm{r}_{\mathrm{i}}\left(\mathrm{t}_{\mathrm{i}}-\mathrm{t}_{\mathrm{i}-1}\right) \\
& =-3 \mathrm{r}_{\mathrm{i}-1}-2 \frac{\mathrm{dr}(\mathrm{i}-1)}{\mathrm{d} \tau}+3 \mathrm{r}_{\mathrm{i}}-\frac{\mathrm{dr}(\mathrm{i})}{\mathrm{d} \tau} \\
\mathrm{a}_{4} & =2 \mathrm{r}_{\mathrm{i}-1}+\dot{\mathrm{r}}_{\mathrm{i}-1}\left(\mathrm{t}_{\mathrm{i}}-\mathrm{t}_{\mathrm{i}-1}\right)-2 \mathrm{r}_{\mathrm{i}}+\dot{\mathrm{r}}_{\mathrm{i}}\left(\mathrm{t}_{\mathrm{i}}-\mathrm{t}_{\mathrm{i}-1}\right) \\
& =2 \mathrm{r}_{\mathrm{i}-1}+\frac{\mathrm{dr}(\mathrm{i}-1)}{\mathrm{d} \tau}-2 \mathrm{r}_{\mathrm{i}}+\frac{\mathrm{dr}(\mathrm{i})}{\mathrm{d} \tau}
\end{aligned}
$$

By substituting these coefficients into the equation (4), three polynomial spline functions can be obtained

$$
\begin{aligned}
r(\tau)= & r_{i-1}+\frac{d r(i-1)}{d \tau} \tau+\left[-3 r_{i-1}-2 \frac{d r(i-1)}{d \tau}+3 r_{i}-\frac{d r(i)}{d \tau}\right] \tau^{2} \\
& +\left[2 r_{i-1}+\frac{d r(i-1)}{d \tau}-2 r_{i}+\frac{d r(i)}{d \tau}\right] \tau^{3}
\end{aligned}
$$

Or

$$
\mathrm{r}(\tau)=(1-\tau)^{3} \mathrm{r}_{\mathrm{i}-1}+3 \tau(1-\tau)^{2}\left(\mathrm{r}_{\mathrm{i}-1}+\frac{\chi_{\mathrm{i}-1}}{3}\right)+3 \tau^{2}(1-\tau)\left(\mathrm{r}_{\mathrm{i}}-\frac{\chi_{\mathrm{i}}}{3}\right)+\tau^{3} \mathrm{r}_{\mathrm{i}}
$$

$$
\text { type, } \chi=\frac{\mathrm{dr}}{\mathrm{d} \tau} \text {. }
$$

\section{Analysis of the Velocity and Contour Error at Corner}

How to maintain the lifting speed smooth especially at the corner during the process is a no negligible point when it comes to tool life and machine working stability. As it appears in figure 4:

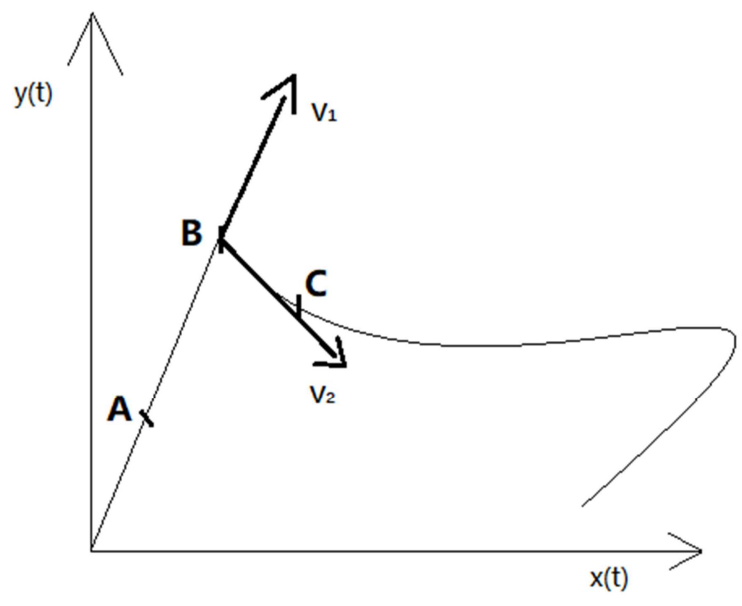

Figure 4. Corner contouring

To solve this problem over, an analysis the maximum allowable velocity and contour error of transition curve. When a control of the contour error at the corner is done, the maximum distance needed for the deceleration can be calculated and the maximum allowable speed at the beginning of the corner transition can also be defined. The vector transition algorithm takes account of the velocity smoothing and contour error in the corner transition.

The hypothesis will be that: the speed curves of each processing section are based on the trapezium velocity curve. The two processing sections $\mathrm{S}_{1}$ and $\mathrm{S}_{2}$, directions of motion are appeared in Figure 5.

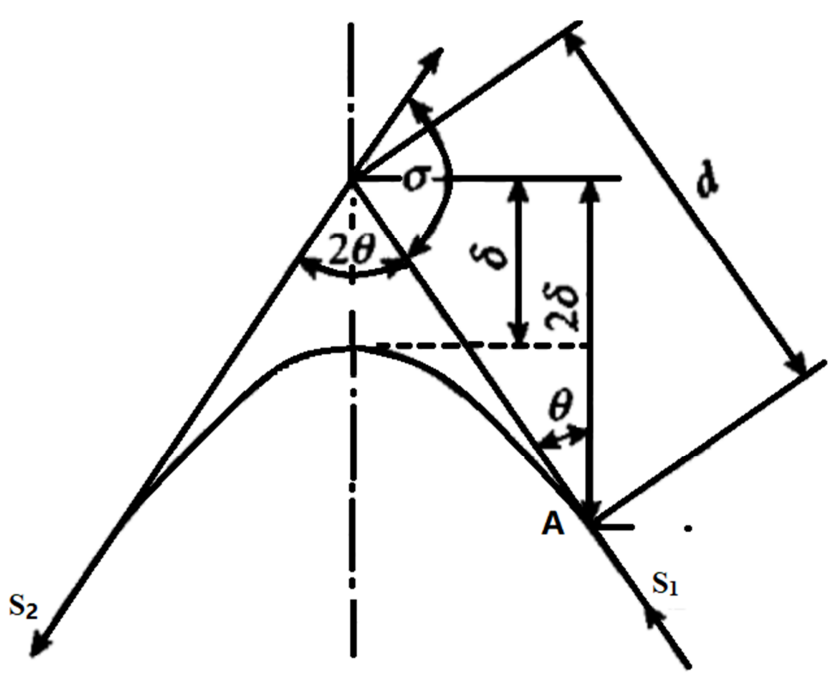

Figure 5. Analysis of velocity at the corner point.

The angle $\sigma$ is the angle of the two motion vectors, $v_{1}$ as the unit vector of the speed at the end of the processing section $S_{1}$ and $v_{2}$ as the unit vector of the speed at the beginning of the processing section $\mathrm{S}_{2}$ then:

$$
\sigma=v 1 v 2
$$

Thus, it can be obtained:

$$
2 \theta=2 \pi-\sigma
$$

When the transition at the corner is between the straight line and arc or arc and arc are, the end of the unit vector direction or the starting unit vector direction of a circular arc is the end point or the starting point of the arc the tangent direction.

As appeared in figure 3-4, a deceleration through a distance $\mathrm{d}$ is supposed, $\mathrm{S}_{1}$ velocity drop to zero; the acceleration of the trapezoid velocity curve is considered; the shortest distance between the corner vertex and the transition curve is $\delta$, there:

$$
\mathrm{d}=2 \delta / \cos \theta
$$

Regarding to the hypothesis, there is an ability to calculate the velocity at the point A: 


$$
\mathrm{v}_{\mathrm{A}}=a t
$$

There:

$$
\mathrm{d}=\frac{1}{2} \mathrm{a}\left(\frac{\mathrm{v}_{\mathrm{A}}}{\mathrm{a}}\right)^{2}
$$

The speed of the transition at the corner is introduced by the formula (11) and (12):

$$
\mathrm{v}_{\mathrm{b}}=2 \sqrt{a \delta / \cos \theta}
$$

When the feed speed is less than or equal to the starvation a vector transition will start.

From the above know $\delta$ and the maximum allowable speed at the corner transition is proportional. Therefore, the transition speed can be controlled by controlling the profile error $\delta$, so that the shape error control can be done.

\section{System Components}

Experimental equipment and platform will includes PC, motion control card and welding table. On the PC, providing a human-machine interface by software programming, motion controller is selected by the American GALIL company motion control card, using high performance microprocessor as the core processor, can complete a weld in plan with meet of the real-time position at the very suitable welding speed, all control with servo control filtering and other functions, can be developed in the Windows platform application software, which is composed by a variety of control system. The purpose of this experiment through $\mathrm{X}$ and $\mathrm{Y}$ moves, a welding head tool is going to be able to weld different trajectories in plan, $\mathrm{Y}$ curve in $\mathrm{X}$ plane. The welding table is driven by servo motors in two directions, $\mathrm{X}$ and $\mathrm{Y}$, and can be carried out with GALIL card. And the $Z$ axis ensures the up down move of the welding head. [12]

\section{Conclusion}

Friction stir welding process is a quite new process that has a big potential of use because of its characterization of being friendly with the environment: no fumes and no use of filling materials. Only for the main reason to protect our environment which getting worse and worse due to daily use chemical we must find a way to make a widely use of FWS process. To study its flexibility to weld paths by low cost is going to introduce it in others fields not only heavy manufacturing.

\section{References}

[1] Dong Chun Lin, Luan red, off the bridge friction stir welding: Welding in aerospace, prospects of application and development of the industry, 2009 (11): 25-31.

[2] Babu, A. S. and Devanathan, C., "An Overview of Friction Stir Welding," Int. J. Res. Mech. Eng. Technol 3 (2), 259-265 (2013).

[3] XIA Luosheng, ZHU Shuhong, LU Duanmin, the Study of Open CNC System for Two-dimensional FSW Equipment Based on PMAC. Zhangjiajie Institute of Aeronautical Engineering, Zhangjiajie 427000, CHN; Central South University, Changsha410083, CHN. 1994-2016 China Academic Journal Electronic Publishing House.

[4] G. C. Jadhav1, R. S. Dalu2, Friction Stir Welding - Process Parameters and its Variables: A Review, Research Scholar, Mechanical Department, Govt. Engineering College, Amrawati-444601, India; Department of Mechanical Engineering, Govt. Engineering College, Amrawati-444601, India. IJECS Volume 3. Issue 6 June, 2014 Page No. 6325-6328.

[5] Ammouri, A. and Hamade, R., "On the selection of constitutive equation for modeling the friction stir processes of twin roll cast wrought AZ31B," Materials \& Design 57, 673-688 (2014).

[6] W. R. Longhurst, A. M. Strauss, and G. E. Cook, Enabling automation of friction stir welding: the odulation of weld seam input energy by traverse speed force control, J. Dyn. Syst. Meas. Control. 132 (2010) 041002.

[7] Xing Li, Koll dawn, Luan Guo Hong, Dong Chun Lin, The influence of the shape of the stirring needle on the formation of the $\mathrm{S}$ curve of the weld seam of friction stir welding (FSW). Nanchang Aeronautical University, Nanchang, Jiangxi 330063; China Friction Stir Welding Research Center, Beijing 100024).

[8] Tabatabaeipour, M., Hettler, J., Delrue, S. and Van Den Abeele, $\mathrm{K}$., "Non-destructive ultrasonic examination of root defects in friction stir welded butt-joints," NDT \& E International 80, 23-34 (2016)

[9] Jiafeng Wu, Rui Zhang, Guangxin Yang, (2015) "Design and experiment verification of a new heavy friction-stir-weld robot for large-scale complex surface structures", Industrial Robot: An International Journal, Vol. 42 Issue: 4, pp. 332-338, https:// doi.org/10.1108/IR-01-2015-0009.

[10] Tsai M S, et Al. Development of an integrated look-ahead dynamics-based NURBS interpolator for high precision machinery [J]. Computer-Aided Design, 2008, 40: 554 566.

[11] Yeh S, Hsu P. Adaptive-feed rate interpolation for parametric curves with a confined chord error [J]. Computer-Aided Design, 2002, 34: 229-237.

[12] Yeh S, Hsu P. The speed-controlled interpolator for machining parametric curves [J]. Computer-Aided Design, 1999, 31: 349-357. 